\title{
CORRECTION
}

View Article Online

View Journal I View Issue

Check for updates

Cite this: RSC Adv., 2021, 11, 11387

DOI: $10.1039 / \mathrm{d} 1 \mathrm{ra90090k}$

rsc.li/rsc-advances

\section{Correction: Efficient biomass saccharification using a novel cellobiohydrolase from Clostridium clariflavum for utilization in biofuel industry}

\author{
Asma Zafar, ${ }^{a}$ Muhammad Nauman Aftab, (iD *b Anam Asif, ${ }^{b}$ Ahmet Karadag, ${ }^{c}$ \\ Liangcai Peng, ${ }^{d}$ Hasan Ufak Celebioglu, ${ }^{e}$ Muhammad Sohail Afzal, id ${ }^{f}$ Attia Hamid ${ }^{b}$ \\ and Irfana lqbal ${ }^{9}$ \\ Correction for 'Efficient biomass saccharification using a novel cellobiohydrolase from Clostridium \\ clariflavum for utilization in biofuel industry' by Asma Zafar et al., RSC Adv., 2021, 11, 9246-9261, DOI: \\ 10.1039/D1RA00545F.
}

The authors regret that in the original article, the name and affiliation for one of the co-authors (Hasan Ufak Celebioglu) were incorrectly given. The correct name and affiliation are shown here.

The Royal Society of Chemistry apologises for these errors and any consequent inconvenience to authors and readers. 